\title{
Invenção mitopoética do mundo contemporâneo de $A$ paixão, de Almeida Faria
}

\author{
Pedro Carlos Louzada Fonseca*
}

\begin{abstract}
Resumo: Este artigo examina a criação ficcional de $A$ paixão (1965), primeiro romance da chamada Tetralogia lusitana, de Almeida Faria. Com base na crítica mítica, estuda a invenção mitopoética do mundo contemporâneo representado no romance. Verifica que o autor critica a realidade portuguesa da tradição vis-à-vis forças revolucionárias do país nos anos 1970. Para tanto, ele constrói a linguagem e a narrativa do romance com base na força expressiva e simbólica do mito e seus elementos arquetípicos. A criação literária de Almeida Faria defende o ponto de vista teórico e crítico de que a literatura pode fazer crítica histórica sem deixar de ser poética.
\end{abstract}

Palavras-chave: crítica mítica; romance português contemporâneo.

\begin{abstract}
This article examines the fictional creation of The passion (1965), first novel in Almeida Faria's so called Lusitanian Tetralogy. Based on the mythical criticism, it studies the mythopoetic invention of the contemporary world represented in the novel. Also, it verifies that the author criticizes the Portuguese reality of tradition vis-à-vis revolutionary forces in the country in the 1970's. In order to do so, he constructs the language and narrative of his novel based on the expressive and symbolic force of myth and its archetypical elements. Almeida Faria's fictional creation defends the theoretical and critical point of view that literature can do historical criticism without been poetical.
\end{abstract}

Keywords: mythical criticism; contemporary Portuguese novel.

A literatura portuguesa contemporânea, principalmente a partir do primeiro modernismo, a chamada Geração de Orpheu (1915-1926), tem se caracterizado pela procura incessante de novas técnicas e estratégias retóricas. Tais achados, contrapostos à tradição da vernaculidade, propõem a invenção, o reaproveitamento de formas e renovações técnicoexpressivas próprias do que já convencionou chamar de experimentalismo polivalente. A prosa de ficção move-se, por assim dizer, em busca de uma expressão pós-vanguardista qualificada pelo gosto da exceção e pelo exotismo. A crítica literária tem considerado não só o ficcionista como também o português como condicionados por nítidas barreiras estéticas: de um lado, a autoridade canônica da vernaculidade panteonizada (Camões, Camilo, Eça, Fernando Pessoa); de outro, e já nos limites da superação desse verdadeiro "peso" clássico, a problemática dialética da difícil relação estabelecida entre novidade e sanção pública

\footnotetext{
" Professor Titular de Literatura Portuguesa do Programa de Pós-Graduação em Letras e Linguística e da Faculdade de Letras da Universidade Federal de Goiás.
} 
inclinada, por tradição, à perpetuação de modelos consagrados, relutante em dar crédito à criatividade inovadora das chamadas virtuosidades experimentais da novíssima literatura ${ }^{1}$.

Apesar de tal consenso, os ismos vanguardistas de certa forma logram responder ao desafio internacionalizador do século XX e à crescente complexidade do progresso, acabando por virtualmente obliterar o estatuto da ficção tradicional, principalmente os seus modos de fruição estabelecidos por uma intelligentsia conservadora. O criador literário, já nos princípios do século, alerta-se com a constatação de que a artisticidade consistia, sobretudo, numa manipulação retórica continuamente experimental. E os mais perceptivos bem cedo começam a rejeitar as soluções de um arcaico matrimônio do romantismo com o realismo, união impressionista que ainda caracterizava grande parte da melhor literatura produzida no decorrer do século. Entretanto, o principal aspecto renovador dos novíssimos estaria na revisão do tradicional princípio de centralidade da palavra literária entendida como logos, isto é, como transparente ao significado presente no modus operandi do pensamento e da mentalidade ocidental. Essa problemática, já bastante analisada pela teoria crítica pósmodernista, registra, entre os representantes da crítica atual em língua portuguesa, a presença de Haroldo de Campos (1971, p.7-9), a detonar, com o seu ensaio sobre o sequestro do barroco na Formação da literatura brasileira, a tese culturalista-logocêntrica de Antonio Candido.

É em referência a esse bastante sucinto panorama histórico-literário - e correndo-se o risco da simplificação, entretanto, aqui justificada por seu caráter introdutório - que o presente estudo da artisticidade de Almeida Faria concentra-se em A paixão (1965), o primeiro volume da chamada Trilogia lusitana (1983) que, na realidade, forma uma tetralogia composta pelos seguintes livros: Cortes (1978), Lusitânia (1980) e O cavaleiro andante (1983). A paixão é de especial interesse para os propósitos do presente estudo, pois, ao buscar a criatividade da linguagem na sua inerência de forma e de estrutura narrativa (cf. TORRES, 1976, p.53), caracteriza o fazer da modernidade que, para além da referencialidade mimética da realidade, concentra-se, entre outros aspectos, no poder auto-referencial da palavra literária.

$\mathrm{Na}$ literatura portuguesa, essa concomitância experimental encontra, na multifacetada poesia de Fernando Pessoa, formas pioneiramente renovadoras, com a criação dos seus ismos

\footnotetext{
${ }^{1}$ Já se tem reconhecido essa peculiar e problemática superação de Pessoa em relação à herança camoniana vis-àvis as possibilidades de intenção renovadora apresentadas pela novíssima literatura portuguesa em relação à tradição (cf. MELO E CASTRO, 1984, p.5-23, 41-57). Do ponto de vista antropológico-cultural, é de se crer que tal dialética da renovação transcenda a simples periodologia estética para se situar na própria formação histórica da mentalidade portuguesa baseada numa complexa relação entre arcaísmo e modernidade, a partir da transição do medieval para o período moderno (cf. HOLANDA, 1969, p.103 e passim; CHIAMPI, 1980, p.100).
} 
vanguardistas e do seu projeto ortonímico e heteronímico. Assim é que, situado nos quadros dessa tradição reformadora, Almeida Faria posiciona-se solidamente como um continuador. Já com o seu primeiro romance, Rumor branco (1962), recebe imediato reconhecimento, apesar de influenciado pelo modismo do nouveau roman então em voga. O próprio autor reconhece esse aspecto que Óscar Lopes associa ao "novo romance", principalmente representado pelo seu aparato formal (cf. TOMLINS, 1981, p.334).

Seguindo a linha experimentalista da literatura portuguesa nos anos 60, A paixão (escrita em 1963, mas só publicada em 1965) dá continuidade à forma e estilo experimental de Almeida Faria. Alinhando-se com essas idéias, João Gaspar Simões comenta sobre certo virtuosismo verbal presente na linguagem do romance:

Já não é monólogo o inintempto fluir das suas frases umas vezes líricas, outras transcritivas do discurso oral? Não. É isso, que reforça, por certo, o apreço dos cultores de um género novo de romance - o romance-linguagem - a nós, que ainda lemos pela velha cartilha, trava-nos o entusiasmo.

SIMÕES (1966, p.17).

Almeida Faria entende que, no discurso literário renovador, deve haver uma correspondência funcional entre novidade do conteúdo e reformulação da expressão, única maneira pela qual os ideologemas (cf. WHITE, 1989, p.145-146) podem ser subvertidos. Verifica ainda que o experimentalismo formal, apesar do seu caráter disjuntor, não deve comprometer a apreensão do que qualifica como real na literatura, isto é, a sua qualidade poética centrada no homem, no seu potencial de humanidade. Objetos e coisas em si mesmos não são o centro da sua ficção, visto que para ele, como para muitos dos seus contemporâneos, poesia, entendida como criação artística, não deve separar o sujeito do objeto.

Se essa elaboração poética do real adquire um sentido de verdade devido ao seu conteúdo humano recriado através da experimentação formal, então o seguinte truísmo relativo à criação ficcional de Almeida Faria pode ser proposto: verdade é o critério da forma. E o ato da criação não seria mais do que a busca da forma e estrutura perfeitas. Dessa maneira, justifica-se a obsessão da modernidade portuguesa pela tríade estilo-forma-estrutura em nome da verdade como realização artística. Fernando Mendonça percebe essa mesma verdade no profundo humanismo de A paixão:

Esta narrativa torrencial de poesia e verdade é um romance, na mais exata consecução do gênero literário. Não é simplesmente uma narrativa, como possa ser anunciado (e já foi), pois ela manuseia as substâncias residuais da natureza humana, recria os atos da sagração humana, abre enfim e necessariamente a palinódia das relações humanas. Que mais seria preciso para fazer um romance? Além do mais, estrutura-se, do primeiro ao último capítulo, um mundo de pessoas que formam elas próprias um sistema girante. 
cit. em TOMLINS (1981, p.340, n. 9).

Para a análise da artisticidade formal vis-à-vis essa dimensão humana em A paixão, o próprio Almeida Faria define estrategicamente o que entende por narrador e criador. $\mathrm{O}$ narrador seria um mero agente do desenrolar dos acontecimentos, enquanto que o criador carregaria em si a responsabilidade do poeta (na tradição grega ou alemã do der Dichter), qual seja, a de descobrir e dar expressão a um novo mundo a partir da realidade conhecida, produzindo uma nova forma de ser real:

Narrador é o que conta simplesmente histórias, que podem ser belíssimas e verdadeiras obras primas do gênero narrativo, da arte de contar (...) Mas criador é o que tira da realidade um mundo que de fato não existia nela, é o poeta, o demiurgo, aquele que justifica a afirmação de que "a natureza imita o que a obra de arte lhe propõe", ou que o propósito do mundo é um livro.

FARIA (1967, p.5)

Essa diferenciação é de crucial importância para a verificação da autoridade narrativa em Almeida Faria porque revela não apenas a consciência teórica do autor, mas também indica uma característica essencial da sua cosmovisão poética: a invenção de novos símbolos para a realidade. Assim é que o mundo de A paixão baseia-se, sobretudo, na redução da realidade a um tratamento cosmológico cujos acordos éticos são reduzidos esteticamente a componentes essenciais que regem relacionamentos humanos caracterizados por qualidades arquetípicas, as quais, transpostas da sugestão mitopoética, identificam aspectos culturais e sociais bem determinados. A condensação dos elementos formais - enredo, tempo, espaço, personagens e recursos técnico-expressivos - confere à narrativa do romance uma atmosfera de verdadeira tensão dramática, que se verifica igualmente no domínio retórico, ao nível da enunciação do discurso, particularmente na maneira pela qual as personagens são narradas: uma sutil combinação de focos narrativos distribuídos entre o autor-narrador (criador) e a auto-narração das várias vozes (personagens) do discurso. Tudo isso tendendo a produzir um efeito harmônico próprio do convencimento retórico e do gosto estético. O que vale dizer que a poesia (ainda no sentido de criação) não se encontra na realidade do mundo natural e sim na elaboração artística que produz novos significantes e sentidos. Essa parece ser mesmo a finalidade da elaboração figurada e simbólica que a realidade trivial de um dia de vida das personagens adquire como significado último e universal em A paixão.

O seu mundo humano revoluteia-se ao redor de dez personagens que compõem uma célula familiar problemática: o pai e a mãe (Francisco e Marina), a unidade patriarcal e proprietária; os filhos, desde a idade pubertária (João Carlos, André e Arminda) até a infância (Jó e Tiago), e os criados da casa (Piedade, Estela e Moisés). O transcorrer de apenas um dia 
na vida de uma herdade do Alentejo corresponde a sua realidade exterior à vivência interior das personagens. O tempo e espaço físicos transubstanciam-se em categorias míticas ao refletirem sonhos, desejos, visões, fantasias e projeções das personagens. Esse espaço alentejano de denso simbolismo é, por isso mesmo, o lugar da deflagração de arquétipos cósmicos característicos de um microcosmo instável, cujas tensões internas indicam um ritmo dissoluto. Ironicamente, esse material em dissolução fornece ao autor-narrador uma competência retórica que reflete um máximo de concentração inventiva em virtude de um mínimo de imitação mimética. Por outras palavras: a retórica narrativa de Almeida Faria forma-se na medida em que a realidade concreta entra em tensão dialética com o seu correspondente simbólico. E a síntese final dessa situação dialética verifica-se enquanto linguagem, forma, estilo e estrutura, cujo simbolismo ético se relaciona ao tratamento estratégico da distância foco-narrativa entre autor-narrador e personagens (cf. CRUZ, 1966, p.11).

Almeida Faria coloca-se a meio termo entre a onisciência do narrador e a individualidade subjetiva das personagens, entre a fechada ilusão mimética e o simbolismo plurivalente, entre a reprodução típica e a sugestão interpretativa dos arquétipos, criando nesse embate de possibilidades a qualidade mitopoética dos seus conteúdos. As personagens de A paixão representam uma construção retórica baseada na função do significante. São seres-de-linguagem, que não reproduzem apenas hábitos comuns da tradicional caracterização romanesca baseada na transparência da palavra em função do seu significado estabelecido. Nesse sentido, a sua aparentemente visível opacidade resulta do denso e fluido simbolismo que as envolve, mais sugerindo do que propriamente classificando, dando-lhes o excesso próprio das verdadeiras vitalidades.

Num universo de caracterização assim tão difusa, em que as personagem parecem não evoluir mas operar em circunvolução, a ação, o espaço e o tempo narrativos tendem a perder os princípios naturais da dimensão épica, reduzindo-se a um mínimo de conteúdo episódico e circunstancial. E é aqui que o reducionismo retórico de Almeida Faria trabalha nos limites de uma absoluta contenção de elementos formais e estruturais. Abstrai-se ao máximo da expansão cronológica e espacial para penetrar em verticalidade nas propriedades metafísicas da ação, do tempo e do espaço sempre referidos às personagens. Entretanto, tal projeção em profundidade é apenas aparentemente complexa porque a transcendência de significados em Almeida Faria, a sua difusa sugestão simbólica, podem ser referidas a imagens de natureza e função arquetípicas, nitidamente recorrentes na narrativa. E isso pode ser principalmente justificado se for levado em conta o fato de que a narrativa demonstra, nos seus momentos 
metadiegéticos, uma forte propensão do autor-narrador para a atualização do simbolismo em referência histórica e cultural, ou seja, do tempo e do contexto da época de sua escritura.

A paixão integra-se no rol das mais recentes produções da literatura portuguesa caracterizadas por uma função afetivo-emocional apelativa ou "emossêmica" (cf. MELO E CASTRO, 1984, p.132-134), que adquire a força de uma verdadeira pulsão. Trata-se da demonstração urgente do princípio da suficiência e da necessidade da vida. A configuração dessa realidade encontra a sua expressão mais íntegra e plena na relação entre o mítico e o poético, na associação do mythos (no sentido de linguagem e realidade) com a poiesis (no sentido de criação, passagem de um estado de não-ser para o estado de ser). O conteúdo e a forma buscados para essa combinação funcional expressam-se através da montagem de um discurso em que imagens simbólicas superpõem-se à designação da realidade externa que, isomorficamente, corresponde a variados estados interiores das personagens. Tal realidade apresenta-se, sobretudo, em termos de sujeição condicional que exige uma maior ou menor submissão, cujo sentido é sempre projetivo, quer ao nível da consciência ou da subconsciência. E a natureza dessa projeção liga-se virtualmente à função básica que o mito possui, qual seja, a superação. Assim é que as personagens de A paixão, de uma forma ou de outra, buscam sempre uma realização ulterior que se apresente satisfatória. Cristina Robalo Cordeiro Oliveira (1980, p.61) analisa essa problemática verificada nos níveis estrutural e temático, "como reflexos fragmentários e fugidios, através de certas estruturas e elementos essenciais, que se repetem com uma freqüência significativa e que se situam, quase sempre, num plano inconsciente: os temas". Refere-se a autora aqui aos arquétipos míticos responsáveis por aquele sentido de superação que habita o mais íntimo das personagens, uma vez que obcecadamente todas elas lutam por uma posse e um extravasamento de energias que possam justificar principalmente as suas vidas moral e espiritual. Nesse sentido, Cristina Oliveira qualifica a dinâmica dos valores, aos quais os motivos mitopoéticos dão forma e conteúdo simbólicos, como:

um equilíbrio estável e original, baseado numa ordem vital diferente: pela rotura de uma estabilidade secular Almeida Faria chega, assim, a uma nova equação de forças, à reorganização do mundo segundo outro prisma de valores (o da justiça e igualdade sociais, ao nível do conteúdo manifesto do texto).

OLIVEIRA (1980, p.62)

Entretanto, essa nova organização vital referente ao conteúdo histórico-social, que acaba por emancipar-se na leitura integral, passa primeiramente por um processo de mistificação, quando, com certo sentido universalista e transcendente, referencia em termos simbólicos a problemática existencial das situações. Para tanto, a recorrência estrutural e 
paradigmática a um mundo de imagens e motivos arquetípicos organiza o discurso narrativo, cuja análise apenas no plano diegético torna-se, por isso mesmo, insuficiente. A diegesis de $A$ paixão é uma construção bastante simples em termos de trama episódica, considerando que representa um cotidiano pouco ativo nesse sentido. Cristina Oliveira resume-o como

a descrição dos três momentos de um dia na vida de uma família burguesa do Alentejo: um dia, sexta-feira santa, cujos três momentos estão marcados pela divisão dos capítulos (manhã: levantar / azáfama da casa, tarde: calor / fogo, noite: frio / chuva); uma família banal, o pai e as preocupações financeiras, a mãe e as preocupações domésticas, os filhos e os problemas da adolescência ou da juventude; o Alentejo, terra de grandes propriedades, de trigo e calor escaldante.

OLIVEIRA (1980, p. 61)

Entretanto, essa horizontalidade é tratada metadiegeticamente quando certos conteúdos recebem diferentes formas de enunciação através da presença formal de substratos míticos e religiosos integrantes de uma extensa rede de imagens e de motivos simbólicos estrategicamente estruturados. Para uma análise interpretativa desse material figurativo, a contribuição da teoria da significação simbólica, a partir de Northrop Frye, apesar das suas limitações, demonstra-se suficientemente pertinente porque explica a relação existente entre a poética mítica e o tipo de conhecimento por ela proposto. Para tanto, compreende que certas estruturas imagísticas padronizam-se na literatura em correspondência com conteúdos herdados da experiência mítica (os arquétipos), arcana e naturalmente inerentes à cosmovisão humana. Explica ainda que a disposição poética encontra-se intimamente ligada a esses motivos universais, encarregando-se de preservá-los como fonte de inspiração e de expressão ${ }^{2}$.

Apesar de a crítica arquetípica tender a dar especial relevo ao modelo essencialista na classificação do arquétipo literário, considerando-o como um elemento além da história, a possibilidade de seu relacionamento ideológico não deve ser inteiramente descartada em narrativas nas quais o autor-narrador metadiegético apresenta os seus juízos de valor a par com a sua construção mitopoética. Assim sendo, considerações mais analíticas podem ser feitas acerca da possível identificação da arquetipia mitopoética de A paixão. E isto em associação com o que é considerado como equilíbrio estável e original que o seu discurso simbólico busca, com a finalidade de propor uma ordem vital diferente que, rompendo uma estabilidade secular, consegue uma reorganização do mundo (o espaço português dos anos 70)

\footnotetext{
${ }^{2}$ Marc Angenot (1984, p. 41), referindo-se aos estudos de Gaston Bachelard sobre esse elemento, considera-o como "uma imagem que tem raízes no mais longínquo insconsciente, uma imagem que provém de uma vida que não é a nossa vida pessoal e que só se pode estudar referindo-se a uma arqueologia psicológica". Ainda essa noção da origem inconsciente do arquétipo é estudada como pré-logicidade da linguagem mítica, livremente criada e imaginada sem o controle do pensamento racional (cf. MANFRED, 1983, p.15-17).
} 
segundo outro prisma de valores (cf. OLIVEIRA, 1980, p.62). Dessa maneira, o elemento mítico comparece no discurso narrativo de Almeida Faria não só enquanto motivo (arquétipos), mas ainda como forma estruturante. Nesse segundo aspecto, a própria maneira, pela qual certos andamentos do discurso se organizam, indica o reconhecimento de um dos componentes essenciais do mito, qual seja, a temporalidade prescritiva. Mesmo a divisão tripartida - manhã, tarde e noite - indica o tempo cósmico presente em muitas cosmogonias de origem mítica. Ainda mais, esse motivo, também cosmogônico em A paixão, associa-se a outro elemento característico da topologia temporal do mito, o ritualismo. E isto porque, de uma maneira ou de outra, todas as personagens estão tematicamente ligadas a um sentido genésico, na medida em que, com maior ou menor consciência, pretendem sair de uma estrutura caótica para um estado de plenitude vital. Nesse sentido, a temporalidade ritualística - referida em termos de foco-narrativo ora à primeira pessoa, ora à terceira, as quais se alternam sem solução de continuidade - identifica a existência interna e externa das personagens, cujo espaço e tempo físicos nada mais são do que uma realidade elevada à categoria simbólica.

O ritualístico estrutura-se em A paixão não só como estratégia formal na economia geral do enredo mas ainda, de forma específica, como fragmentos narrativos independentes diegeticamente, ligando-se nesse caso a motivos de uma mitologia definida e/ou indefinida. $\mathrm{O}$ discurso de Piedade - a serva mais antiga da família e que é o assunto de abertura da narrativa - serve como exemplo do emprego da ideia do ritual como estratégia formal. A personagem é narrada como agente-objeto de um ritualismo cujo sujeito real é a sua própria condição de servidão. As ações-reflexões de Piedade reproduzem, na duração de apenas um dia de serviço doméstico prescritivo, a rigidez actancial característica da prática ritualística que, através da repetição sistemática ad infinitum, acaba consequentemente por eliminar o sentido de duração do tempo e conferir-lhe um aspecto de intemporalidade. Assim, a personagem, mesmo antes de levantar-se, com "os olhos cerrados e, cansadamente, reconstitui os gestos gastos a fazer; o dia que se segue é-lhe memória negra; assim o percorreu [e tudo sugere que percorrerá], envolta em trevas, por semanas santas que duraram séculos (...)" (FARIA, 1982, p.15). A coerência entre o motivo ritualístico e a forma verbal no segmento de Piedade torna-se tão consistente que mesmo a linguagem e o estilo da passagem refletem a ideia da ordem prescritiva característica do ritual. Isso pode ser verificado, dessa maneira analógica, com o emprego repetitivo de uma sequência de frases no infinitivo, interceptadas parenteticamente por comentários em forma de discurso indireto-livre. Tais marcações parentéticas reforçam ainda mais o sentido de imutabilidade característica do ritual devido a referências a imagens 
de blocos de tempo-acontecimentos inalteráveis na sua repetição, como no seguinte trecho relativo às intermináveis labutas da personagem: "De madrugada (...) levantar-se, descer para a cozinha e enregar o trabalho (...) lavar a louça (...) (durante o inverno a água gela, corta os ossos da gente, faz doer às vezes até o braço acima - dever ser reumático - mesmo ao cotovelo (...) (FARIA, 1982, p.13).

Estruturado sob a forma de fragmento diegeticamente independente, o ritualismo de $A$ paixão liga-se, frequentemente, a uma mitologia de motivos facilmente rastreáveis como, por exemplo, o curto texto que constitui o capítulo segundo do romance, todo ele construído para descrever o ritual de João Carlos, o filho-do-meio da família e uma das personagens principais da obra. Esse ritual, por todas as suas características ligadas à tradição, é sacrifical e motivado biblicamente por arquétipos referentes à prática da imolação do cordeiro pascal. E não é gratuito que, nesse nível simbólico, em passagens posteriores da narrativa de João Carlos - misto de agente-vítima da imolação ou mesmo da auto-imolação -, a personagem passa a ser identificada pelo acrônimo crístico J. C. Apesar dessa especificidade simbólica, o ritual de João Carlos pode ser identificado com o de Piedade, na medida em que ambos têm que cumprir à risca os procedimentos para a prática das ações, em observância estrita da ordem e das condições temporais. Assim, com plena consciência dessas determinações, João Carlos reflete (e com ele o próprio autor-narrador) sobre a maneira como deve ser a hora da imolação e quais os requisitos básicos que a vítima tem que preencher: o cordeiro tem que ser "sem mancha, macho, dum ano" e dever ser sacrificado "dentro da madrugada (...) com a faca que gargantas já abriu antes desta, que a sóis brilhou iguais ao de hoje, que outrora se cobriu do mesmo sangue (...)" (FARIA, 1982, p.16). A passagem se completa, como a de Piedade, com uma promessa de esperança e de redenção, após o sacrifício expiatório. Com a consumação metafórica da carne do cordeiro imolado - como a consumação escarmentada das forças serviçais de Piedade, o que lhe dá uma antevisão catártica com a ideia de um dia poder deixar a casa escravizante -, João Carlos, assim como todos os que expiam com ele, estarão prontos para alcançar as "portas da cidade, são coisas de direito divino, coisas santas, os muros e as portas da cidade" ( ibidem, p.17).

Contraposto à recorrência ao sagrado, a noção de ritualismo verifica-se ainda em referência a conteúdos seculares marcados pela tradição sócio-cultural à qual se encontram sujeitas certas personagens, principalmente aquelas que representam arraigados efeitos de uma educação moral de herança familiar tradicional como, por exemplo, Marina e Francisco. Marina, ao recordar-se do ambiente de outrora, da ancestralidade da casa onde fora criada, 
expressa a sua lembrança através da imagem de um verdadeiro rito de desolação, onde a temporalidade identifica-se pela ideia de um passado terrível e inapelavelmente perpetuado pela sujeição ao infortúnio: "Raparigas de peitos pequenos e de triste olhar, quase velho, mordendo a sua noite e caminhando como uma desgraça pelos corredores, cozinhas, caves, dispensas em que se falava a língua do terror" (ibidem, p.21). Francisco, por sua vez, apesar da sua disposição eufórica em valorizar as virtudes dos seus antepassados, sofre essa mesma opressão de um passado ritualisticamente conservado como contrapeso necessário à significação do presente. Em tais personagens, um verdadeiro memento mori qualifica-as moral e psicologicamente, tornando-as totalmente vulneráveis aos efeitos da decadência. Francisco, por exemplo, reproduzindo uma característica marcante da cultura portuguesa - a de individualizar os seus mitos nacionais ${ }^{3}$-, num misto de fetichismo religioso e saudosismo, contempla uma foto antiga do seu avô, "fundador da gens, da tribo, o chefe deste clã, patrono de larpenate [isto é, palavra-soma que semantiza os espíritos protetores e ancestrais domésticos]: a nuvem sombreada que lhe envolve a cara é o halo mágico que rodeia heróis e sábios (...)" (FARIA, 1982, p.13).

A inter-relação entre motivo mítico e certas particularidades da antropologia cultural portuguesa merece ser considerada, ainda que de passagem, a fim de se avaliar a significativa contribuição que a tradição histórica exerce como tema constante em toda a literatura portuguesa, como é o caso de A paixão. Nesse sentido, a personagem Francisco atualiza a expressão do marialvismo, termo cunhado para significar a centralidade ideológica do conceito de paterfamilias na formação da sociedade portuguesa, sendo a estrutura prepotenciária desse conceito assunto de discussão constantemente retomado nos quadros da cultural nacional ${ }^{4}$. A versão marialva do machismo português é interrogada nas constantes visões e monólogos interiores de Marina, a personagem que mais diretamente sofre as consequências do atavismo primário e ritualístico da decadente posição de chefe de família desempenhada por Francisco, "perdida na indiferença do marido egoísta, dum materialismo primário e infantil (...) que se reduz ao vegetar diário (...) sono, comida, sono, cansaço,

\footnotetext{
3 Essa característica cultural portuguesa, bastante referida na consubstanciação mítico-histórica do Sebastianismo, apresenta-se como consciência crítica em muitos dos representantes da literatura portuguesa contemporânea. Álvaro Manuel Machado (1984, p.84), citando Agustina Bessa-Luís, numa das mais felizes intuições intelectuais da escritora sobre essa problemática, diz que "o português 'trata as idéias como objetos', o que é a negação da história no sentido hegeliano do termo: 'Um destino é, para o português, algo de aplicável ao seu cotidiano; um destino histórico não é nada' (...)".

${ }^{4}$ Fernando Mendonça (1973, p.107), ao estudar a presença do marialvismo em A cartilha do marialva, de José Cardoso Pires, comenta que o autor "incomoda por denunciar mistificações passadistas, de infra-estruturas sócioeconômicas que pretendem desesperadamente ignorar a marcha inexorável da História, embandeirando-se de mitos com os quais julga poder decidir o futuro com a tradição do passado (...) [alimentando-se da] memória das arbitrariedades dos avós (...)".
} 
devassidão, ausência, apatia, espera, sexo e trabalho, café, lavoura, café, conversa, intrigas, dinheiro, paciência (...)" (ibidem, p.125-126).

Ainda em A paixão, o ritualismo assume outras motivações cujas características situam-se entre o sagrado (de procedência religiosa judaico-cristã) e o secular baseado na sugestão do culto da tradição, respectivamente tornados protótipos, conforme se verificou, pelas figuras de João Carlos e Francisco. Nesse caso situa-se a narrativa de Tiago, o filho mais novo da família, incorporando um compósito de elementos míticos e/ou místicos provindos das mais diversas sugestões imaginárias. $\mathrm{O}$ autor-narrador se refere à personagem como o "benjamim (...) aquele a quem os deuses dão qualquer coisa (...) um mítico príncipe russo (...) uma espécie de poeta desgraçado, a quem os olhos insistem em sonhar" (FARIA, 1982, p. 66). Tiago, criança solitária, habituara-se a brincar nos cômoros da quinta, quando chovia e a terra ficava encharcada, fazendo "paciente, figurinhas de barro, cães, mulheres, cavaleiros, automóveis (...) essas rudes esculturas estavam ligadas as chuvas como a hera as árvores (...)" (ibidem, p. 64). Torna-se evidente que a motivação mítica, que referencia a personagem, liga-se ao princípio aquático da criação original, recordando o illo tempore de Mircea Eliade (1959, p.17). Entretanto, esse aspecto do mito em stasis completa-se com o motivo da ciclicidade natural, visto que, num labor constante, o menino Tiago, sempre depois de cada chuva, refazia as suas criaturas com os elementos básicos da vida cósmica - terra, água e sol (fogo) -, "não se lembrando mais das esculturas (...) senão quando chovesse, então recomeçava o seu ritual e obsessão, febril e surdamente (...) [refabricando-as] para que durassem o tempo de uma chuva miúda, que as desfazia em breve..." (p.65). O segredo desse estóico evoluir cíclico "ele só o sabia e sorria por dentro, relembrando a lenda [a Penélope ulissíaca?], fazendo e desfazendo a sua longa teia, e esperando talvez também mas sem saber o quê (...)" (ibidem, p.65-66).

Já para a metade da narrativa, a motivação mítica adquire uma elaboração formal extremamente difusa e complexa em relação ao reaproveitamento que o autor-narrador faz, fragmentariamente, de vários elementos de mitologias conhecidas. E é aqui que a criação mitopoética de Almeida Faria se manifesta com intensa autoridade, uma vez que, contrária à simbiose foco-narrativa anteriormente adotada (combinando a narração em primeira pessoa com a voz do autor-narrador), cede lugar à onisciência da terceira pessoa. Nesse segundo segmento de A paixão, é narrado o incidente de um incêndio que acontece nas plantações dos Cantares (propriedade da família), o qual congrega vários pontos de vista e ações que as personagens manifestam em relação ao sinistro. Entretanto, ex abrupto na economia causal e actancial dos episódios - mas perfeitamente integrado ao nível do conteúdo simbólico que 
informa o discurso narrativo do romance como um todo - surge, inserida na narração do fogo destruidor, uma sequência mitologizante, com suspeitados motivos pagãos e cristãos, sobre a origem cosmológica, entre mítica e mística, desse elemento ígneo (ibidem, p.79-80). A elaboração das imagens que formam a surrealidade dessa mitologia solar caracteriza-se pela figuração final de uma cosmogonia natural intimamente ligada a elementos oriundos do sagrado de natureza crística. Assim é que, depois de uma cataclismática destruição presidida por uma conflagração de deuses pagãos, "foram plantadas muitas cruzes e elas frutificaram amplamente, dum lume assim nasceu o mundo, e dele restam hoje horizontes de fogo, ar de fogo...” (FARIA, 1982, p.80).

Outra faceta da apropriação de motivos míticos em A paixão é aquela que se relaciona com o lendário. Aqui, a personagem de referência narrativa é Arminda, a única filha da família. A personagem relata um caso amoroso entretecido por uma rapariga desconhecida que se apaixona perdidamente pela estátua de um cavaleiro colocada no claustro de uma catedral de uma "cidade ou vila de província, como Évora talvez" (ibidem, p.102). Ao que tudo indica, a narrativa de Arminda, por assemelhar-se a um conto ou lenda conhecida, projeta, na sua consciência criativa, resíduos de motivações míticas, identificados por Joseph Fonterose (1966, p.55), em casos semelhantes, como "characters who may be any sort of persons: deities, human beings, animals; the main characters are not likely to be persons of myth (...) although these are not excluded". Assim sendo, uma suposição de motivos míticos pode ser tentada para a interpretação da narrativa de Arminda: a estátua de pedra do cavaleiro reproduziria, em virtude da sedução que a sua virilidade exerce sobre a rapariga apaixonada do conto-lenda, a metáfora erótica do mito de Pigmaleão. Entretanto, como é próprio da elaboração mitopoética de Almeida Faria, a essa motivação pagã associam-se sugestões extraídas do substrato bíblico, pois o jardim do claustro relembra, através de uma reversão analógica, a alegoria edênica, agora visivelmente deformada. As árvores são descritas "crescendo em segredo, laranjeiras [a Árvore do Conhecimento, revertida] nas quais uma laranja só [o fruto proibido], aqui e além, vermelha e cheia, brilhante de orvalho e já manchada de vil ferrugem velha [o original pecado corrompedor] dentro de reentrâncias (...)" (FARIA, 1982, p.102).

A sintagmatização narrativa do substrato mitopoético de $A$ paixão é o desenvolvimento de uma sequência de motivos simbólicos, cuja emancipação semântica é distribucional e integrativa, compondo um eixo de combinação paradigmática. Tais elementos, por representarem categorias essenciais (universais) à construção mítica, consubstanciam-se na qualidade arquetípica literariamente identificável, conforme indica Frye 
(1966, p.365) como "a symbol, usually an image, which recurs often enough in literature to be recognized as an element of one's literary experiente as a whole”. Em Almeida Faria, conforme se verificou anteriormente de passagem, a arquetipia é bastante identificável em sua recorrência mítica, correspondendo a narrativa com intenções marcadas para além do seu puro simbolismo natural. E aqui pode-se considerar a relação que existe entre o arquétipo de origem mítica e a sua refuncionalização em termos literários ou mitopoéticos ${ }^{5}$, podendo estar ligada a conteúdos ideológicos, culturais e históricos.

As personagens de A paixão, de uma forma ou de outra, encontram-se referidas a um sentido de libertação projetiva, sofrendo cada uma o seu pathos motivado em razão de sofríveis condições morais e/ou sócio-culturais. Verificada a motivação mítica subjacente a essa problemática, encontra-se uma concepção dialética que divide os termos dessa superação entre dois pólos básicos da solução mítica, entretanto intimamente correspondentes: o pólo eufórico e o disfórico. Frye categoriza esses padrões levando em consideração uma classificação de imagens simbólicas positivas e negativas, cuja interação é uma síntese dialética baseada no princípio da circularidade do mito referido natural e culturalmente. Tais imagens simbólicas constituem o que Frye chama de arquétipos harmonizadores e desarmonizadores. À primeira categoria correspondem os arquétipos sancionados por uma "apocalyptic imagery", ou seja,

organizing metaphors of the Bible and of the most Christian symbolism, and they are brought into complete metaphorical identification in the book explicitly called the Apocalypse or Revelation, which has been carefully designed to form an undisplaced mythical conclusion for the Bible as a whole.

FRYE (1966, p.141)

Com relação à categoria desarmonizadora, resultante da inversão caótica e corrompida da ordem divina, Frye a denomina "demonic Imagery". Se o apocalíptico representa uma condição divina, "before the human imagination begins to work on it and before any image of human desire, such as the city or the garden, has been solidly established (...)" (FRYE, 1966, p.147), o demoníaco existe como conseqüência da falência existencial humana, resultante do afastamento do divino tanto na ordem teogônica como na humana. Assim, "just as the apocalyptic in poetry is closely associated with a religious heaven, so its dialect opposite is closely linked with the existential hell (...)" (idem). Em A paixão, o relacionamento das imagens arquetípicas representa a ideia de que tal dialética soluciona-se, finalmente, em

\footnotetext{
5 Esse aspecto estético do arquétipo, Harold C. Knutson (1976, p.6) o reconhece como uma "particular, misterious identity of word and feeling through another form of language, art. (...) A sort of constant palingenesis, at once a sensuous and a spiritual reincamation (...) [which] recovers the fullness of life; but it is no longer a life mythically bound and fettered, but an aesthetically liberated life".
} 
harmonia e de acordo com o modelo circular do mito. Representando os arquétipos os mitos básicos de toda a criação poética ${ }^{6}$, verifica-se, segundo comenta Frye (1963, p.31), "the obliterating of boundaries separating legend, historical reminiscence and actual history.

O sentido de harmonização dos arquétipos, nas suas categorias apocalíptica e demoníaca, é ainda considerado na ficção literária por Frank Kermode sob a noção de clausura determinante da estrutura das aventuras ${ }^{7}$. Em A paixão, as categorias arquetípicas, desde o início da narrativa, podem ser interpretadas segundo esse padrão sincrônico e fechado da intemporalidade e universalidade do mito. Aqui, ambos os tipos de arquétipos funcionalizam a síntese do eschaton como um telos que confere significado e valor simbólicos ao tema da sentida necessidade da vida comprometida pela dessignificação de certos valores tradicionais histórico-culturais nos seus mais aspectos éticos, morais, sociais e espirituais.

A partir do inicial ritualismo arquetípico de Piedade e do apocalíptico sacrifício de João Carlos, todas as demais personagens encaixam-se na relação binária apocalíptico versus demoníaco. Tal classificação pode ser feita considerando-se que, por um processo metanoico, as personagens internalizam arquétipos ritualísticos. Nesse sentido, todas elas sofrem o desastre demoníaco como condição necessária a uma possível superação num futuro que já escatologicamente compõe o presente das suas vidas. Knutson, analisando os arquétipos ligados a essa problemática, classifica-os como

\begin{abstract}
Archetypes of sacrifice, of scapegoat expulsion, or death and resurrection, and the like, [acrescentando que] literary narratives can be reduced to basic stones which express, in their underlying ritual content, primitive human fears and aspirations (...) [and] certain prirnitive desires and anxieties in the collectivity: fear of death, sterility, and disease, longing for life, health, and prosperity.
\end{abstract}

KNUTSON (1976, p.5)

Em consonância com esse modelo apocalíptico dialetizado ao demoníaco, outras personagens de A paixão funcionam como catalizadoras, na medida em que sugerem uma apocalítica consumação final do conflito, uma reunião no illo tempore divino recuperador. Assim, André, o filho mais velho da família, obcecado pelo medo da morte iminente, apesar da sua fúria existencialista e do seu sensual e erótico carpe diem, percebe "ter perdido a

\footnotetext{
${ }^{6}$ John White (1971, p.44), avaliando essa representatividade do arquétipo, concorda que "we can certainly isolate elements of it in many myths and works of literature; and this is what anyone is doing when he calls a literary work mythical"

${ }^{7}$ Essa noção de clausura provém da leitura hermenêutica do Apocalipse bíblico onde "past, present and future are related inextricably", visando a uma conclusão predeterminada, quer desastrosa ou recompensadora. O tempo, nesse caso, é uma categoria teleológica e sem cronologia, um "time of men in certain postures of attentiveness" (KERMODE, 1967, p.141, 148), sendo o advento prometido contemplado no presente, em cada momento da existência atual.
} 
pureza do começo (...) [visto que] depois da dissolução [lhe] assalta uma urgência de claustro (...)" (FARIA, 1982, p.90). Procura, então, a plenitude da consolação intemporal e perene que a ancestralidade dos arquétipos parece lhe conferir. Compraz-se com a busca e o gozo da atmosfera mítica de edifícios antigos "embalsamados ao peso do passado (...) em que coisas e gentes existem para sempre (...)" (idem), os quais fazem a personagem sentir um secreto desejo religioso de cultuar realidades que nunca perdem o seu significado original, "mitos e musas e imagens, pinturas sobre tela e tábua (...) [querendo] levá-los para casa, construindo um sacrário dessacralizado (...) tê-los fixos nos olhos e dormir sob o fixo olhar deles, e vencêlos e sê-1os (...)" (FARIA, 1982, p.90).

Outra personagem ligada a essa mesma intuição do mítico sacralizador é Moisés que, como André, perspectiva-se em referência à morte (ou ao medo-desejo dela) por causa da sua idade avançada e das experiências que passara com a fatalidade. $\mathrm{O}$ mesmo motivo arquetípico do edifício de perene ancestralidade e originalidade temporal referencia Moisés. Contemplando a velha ermida da vila, a personagem reflete sobre a misteriosa razão dos "templos perfeitos sem razão, que gostamos de olhar e em que estamos bem (...) formas belas em si, cuja só substância é serem belas, sem porquê (...)" (ibidem, p.72). A conjugação apocalíptica do illo tempore reflete-se nas impressões que Moisés tem ao venerar uma enigmática inscrição feita numa das paredes da ermida: "Alguém escreveu a faca uma estranha e solitária, ou estranha porque solitária, palavra: sempre (...) ao soletrá-la, a voz sai arrastada, lenta, cava, e contudo, situada no âmago do mundo, voz inominável e sem face do que ainda não é mas olha longe (...)" (FARIA, 1982, p.72) ${ }^{8}$.

Considerações complementares ainda merecem ser feitas acerca de certas personagens que refletem uma inescapável, ou ainda não simplesmente possível, condição de sujeição às limitações do universo mental e cultural em que estão inseridas. A mãe Marina e a filha Arminda, por não se sublimarem apocalipticamente, representam a faceta da dissolução estática e intranscendente da arquetipia demoníaca. Entretanto, essa antítese que as qualifica integra-se dialeticamente no dinâmico plano simbólico que qualifica o projeto figurativo e ideológico de A paixão. Esse parece ser o sentido do sonho infernal de Arminda e o do locus

\footnotetext{
${ }^{8}$ Essa noção da eternidade do espaço sagrado, Eliade a identifica em relação a intemporalidade original da criação divina. Nesse sentido, "the very ancient conception of the temple as the imago mundi, the idea that the sanctuary reproduces the universe in its essence, passed into the religious architecture of Christian Europe..." (ELIADE, 1959, p.17). Frye (1969, p. 96) considera que a posição de centralidade da cidade e, dentro dela, o templo, reproduz a ideia de harmonização entre a criação universal e a cultural. E Joseph Campbell, por sua vez, analisa essa espécie de religiosidade sugerida pelo arquétipo como característica biopsicológica do mito no seu desejo de transcender o medo da morte através da busca da intemporalidade vital, «that of a transcendental yet ubiquitously immanent sacred power (...) that is to say, precedent to the phenomenology of cultural styles (...)" (CAMPBELL, 1969, p.17).
} 
horribilis de Marina. No primeiro caso, a dialética estabelece-se de imediato na sequência narrativa, visto que tal sonho infernal é narrado logo após o capítulo do ritual divinizado de João Carlos. E o motivo de reversão, que aproxima essas duas passagens, consiste na descrição do arquétipo cidade, apocalíptica para João Carlos e demoníaca para Arminda.

Em João Carlos, a cidade apocalíptica, implicando peregrinação, comunhão e redenção através da metáfora pascal, promete uma nova vida de satisfação plena, simbolicamente referida para além das privações contingentes. Estabelece-se, para tanto, a dimensão do tempo eterno, visto que a chegada à cidade divinizada terá lugar "na primavera, no princípio de tudo; o sol cairá a pique sobre nossas cabeças (...)” (FARIA, 1982, p.16-17). Tal caracterização espaço-temporal, além de sugerir o illo tempore, indica ainda a imagem topocósmica da centralidade do lugar sagrado (o eixo do mundo), na medida em que a posição em verticalidade do sol une temporalmente o mundo cósmico ao mundo humano em ascese. Eliade (1959, p.12) explica esse arquétipo em referência à topologia sagrada como o axis mundi, considerado como o ponto de encontro entre o céu e a terra. A já referida descrição da ermida de Moisés lembra essa mesma noção arquetípica, considerando-se que a personagem a contempla como a "um silêncio de sol, tão próxima do céu como dos homens, com varandas rasgadas donde o espaço é palpável (...) (FARIA, 1982, p.71). Opostamente, a reversão demoníaca desse arquétipo divinizado ocorre na descrição cataclismática, avassalada por instintos destruidores, da cidade de Arminda. Nesse conglomerado caótico e parafernálico, agitado por uma compulsiva possessão agressiva, as faces mascaradas das pessoas disputamse diabolicamente com ciúme mórbido, com risos e uivos histéricos de morte:

(corpos furiosos dois a dois uniram-se junto a conjugada conjugação dos astros (...) esgar doido, braços e pernas erguiam para o vácuo e sua união deles era tão fugaz que nem chegava para sê-lo (...) os corpos repetiam o seu rito fatal (...) carros que passavam à luz de candeeiros tinham um fogo branco nos ruídos; as sombras dispersavam sobre o deserto frio; deserto frio, frio (...).

FARIA (1982, p.18).

Tal sociedade anárquica corresponde à descrição que Frye (1966, p.147 e passim) apresenta para o mundo demoníaco como : "a society held together by a kind of molecular tension of egos (...) The inorganic world may remain in its unworked form of deserts, rocks and waste land (...)". Entretanto, como é próprio da dialética arquetípica, a sociedade infernal de Arminda representa o eschaton em relação apocalíptica, principalmente porque o texto fala de uma voz que chama e que propõe a salvação. As cidades dos irmãos reúnem imagens consubstanciadas biblicamente, podendo assim significar a velha e a nova Jerusalém dos Evangelhos. 
Ainda num contexto arquetípico, embora sem referência direta à tradição sagrada, o demoníaco configura o mundo interior de certas personagens, refletindo a sua emotividade frente a experiências decepcionantes, sofríveis e vitimadoras, oriundas de adversidades e/ou fatalidades por que passam. Esse o caso da mãe Marina, esposa reprimida pelo marialvismo, do qual Francisco é o epítome mais imediato. A imagem-chave do demoníaco sacrificador da individualidade subjugada de Marina é o seu leito conjugal que, ironicamente dessignificado, deixa de representar a solicitada imagem romântica do epitalâmio para significar, na percepção da esposa, o seu próprio holocausto, centro macabro de demoníacas sensações destruidoras, onde "o tecto é alto, a cama é muito larga, chega para dois corpos devagar se matarem, tem relevos de fogo, patas de águia fincadas, o sobrecéu ausente para espantar o medo (...)" (FARIA, 1982, p.19). Lembrando-se da antiguidade do leito, considera-o a personagem como um ninho ancestral mórbido pela contaminação da lascívia, dos nascimentos deformados e das mortes degradadas. Marina é o símbolo invertido da mater genetrix devido à disfuncional infertilidade em razão da velhice e da submissão incondicional às estruturas de um patriarcalismo aniquilador. A personagem epitomiza maravilhosamente o motivo do desgaste tanatológico que pontilha toda a narrativa de A paixão. Esse motivo expressa-se com uma força imagética recorrentemente arquetípica, semelhante ao que Raimon Panikkar (1979, p.155) define como mitema da "Presence of Death" inerente à condição humana, "a definite problematic (...) to show how life on earth is a constant confrontation with death at every level. To face death is inherent to the human condition (...)".

A vertente demoníaca do mitema da morte representa mais uma contraposição dialética ao mitopoético sentido da necessidade qualitativa da vida, considerado como a ultimada força motriz do discurso de Almeida Faria, visto que, conforme ainda propõe Panikkar (1979, p.157) ao tratar do mitema da "Solidarity of Life", "what matters is the quality of life, not the quantity, because life as such is a qualitative value and consequently unquantifiable". Estruturalmente, esse aspecto da qualidade simbólica e valorativa da vida verifica-se inclusive no fato de a economia narrativa depender menos das ações e episódios do que das constantes reflexões das personagens em frequente simbiose com a voz do autornarrador. $\mathrm{O}$ arquétipo da morte por expiação encontra no locus horribilis do quarto conjugal dos pais, imagem prototípica do peso morto da estrutura familiar, o seu catalizador mais funcional. Dessa maneira, o marido que dorme é associado por Marina à sensação de estar vendo, do seu lado, um cadáver arquetípico que repousa "em qualquer cama de qualquer quarto de qualquer casa, repousa frio e longo, fino e grave como todos os mortos, sob o selo de cera de sua face morta (...)" (FARIA, 1982, p.17). Por outro lado, a problemática 
tanatológica de Marina, reversora do mito primaveril e cômico do matrimônio, qualifica-se tragicamente como uma paródia demoníaca do casamento, representando, conforme comenta Frye (1966, p.150), uma categoria que se engendra por meio de "images of dead mechanism which, because it does not humanize nature, is unnatural as well as inhuman".

Além da manifestação do arquétipo morte, diretamente ligada ao demoníaco, tal motivo torna-se atenuado, em certas passagens, por metáforas cósmicas de natureza líricodramática, uma vez que expressam conteúdos emocionais de algumas personagens. Assim, o velho Moisés percebe a inexorabilidade da morte identificada com o poder cósmico da noite escura que "ocupa as enormes esferas (...) a noite longa e longa, morta, vinda do outro lado; é noite, átrio da morte, sem esforço e sem descanso girando sobre a lua (...)" (FARIA, 1982, p.30). Entretanto, tal arquétipo assim metaforizado representa-se, sobretudo, pelo seu caráter demoníaco através das ideias de destruição e aniquilamento como, por exemplo, na descrição de André, cuja noite é uma "deusa das trevas, filha do céu e da terra, toda feita de mamas, esposa-fêmea dos inferno (...) hora do príncipe das trevas (...)” (ibidem, p.56). O aspecto destruidor da noite é conotado pela inversão da simbologia arquetípica do feminino como princípio da criação, sendo composto pela equivalência simbólica da cor negra, tradicionalmente ligada ao caos das trevas (CIRLOT, 1962, p.218). O estado caótico das trevas é ainda labirinticamente tratado por André em outra passagem dos seus frequentes pesadelos: uma "torre, um escuro arranha-céu em obras, com escadas e cubículos, corredores e quartos (...) [em que a personagem sonha estar] caminhando porém como um forçado, uma alma penada por caves de castelos (...) tomado do pânico de ir morrer (...)" (FARIA, 1982, p.73); passagem esta que Frye, na sua dialética arquetípica, identifica como "labyrinth or maze, the image of lost direction (...) [em oposição à direção retilínia do divino] temple or One Building of Apocalypse (...)" (FRYE, 1966, p.150). Ainda esse mesmo motivo da desorientação nas trevas é sugerido na descrição que o autor-narrador faz do cortejo do Senhor Morto na noite daquela sexta-feira santa, quando a atitude dos devotos, já antevendo o eschaton apocalíptico da Ressurreição, é perturbada pateticamente pelo súbito apagar das luzes: "como uma súbita intervenção divina [e aqui está a ironia do patético], a iluminação eléctrica extinguiu-se simultaneamente em toda a vila (...)" (FARIA, 1982, p.136). O autornarrador, como em exemplo anterior, compara a desorientação noturna com o nascimento do medo arquetípico que se origina das ansiedades e dos terrores teogônicos do homem como "ser prisioneiro do pânico de antiguíssimos deuses" (ibidem, p.150).

O exame da solução dialética entre o apocalíptico e o demoníaco em A paixão, dada a densidade simbólica da mitopoesia dos seus motivos, constitui uma tarefa dificilmente 
esgotável. Isso porque, para além da crítica sincrônica, que considera esse substrato em relação à espacialização do tempo - ignorando a sua dimensão transformadora, a exemplo de Frye e dos defensores da escola do mito e do ritual -, outra aproximação a essa problemática deve ser feita, isto é, aquela que considera também o tempo como duração, responsável por mudanças irreversíveis na realidade. Tal temporalidade, sensitivamente mais humanizada do que a anterior, é considerada por Geoffrey Hartman (1970, p.363) quando comenta que "Frye fails to bring together the form of art and the form of historical consciousness". Essa perspectiva diacrônica do simbolismo mítico literário é reconhecida também por Ernst Cassirer que, formulando a sua teoria das formas simbólicas, comenta que a consciência mítica natural, assim como a teoria literária que a defende, não é capaz de apreender a irrepetível qualidade, a portentosidade do tempo histórico, que se caracteriza justamente por uma dimensão humana mais funcional e significativa. Nesse sentido, Cassirer distingue a consciência mítica (espacial e natural) da consciência histórica, na medida em que "the meaning of historical time is built not solely from recollection of the past, but no less from the antecipation of the future as on the contemplation and actualization of the past" (CASSIRER, 1957, p.182). Tais observações parecem ser de especial importância para a análise da diacronização do conteúdo mítico-arquetípico de $A$ paixão, isto é, para a verificação da possibilidade da transversão do simbólico à dimensão do seu contexto histórico-cultural. Assim, pode-se considerar que a forma mítica e simbólica do discurso narrativo de Almeida Faria, enquanto signo, constitui uma espécie de mitologia historicizada, em consonância com o que Paul Ricoeur entende por lógica pragmática do signo linguístico, isto é, falar de alguma coisa para um alguém determinado, visto que "it is necessary then to balance the axiom of the closure of the universe of signs by the attention to the primary function of language, which is to say. In contrast to the closure of the universe of signs, this function constitutes its opennes or its opening"(RICOEUR, 1974, p.84) ${ }^{9}$.

Tais considerações permitem distinguir, na clausura natural do simbolismo mítico e arquetípico de A paixão, um processo de significação passível de ser interpretado em relação a coordenadas verificadas a partir do seu contexto histórico. Entretanto, essa aproximação entre clausura do signo simbólico e a possibilidade de sua abertura histórica, ainda teoricamente, não parece tão facilmente transitiva. De um lado da questão, coloca-se a

\footnotetext{
${ }^{9}$ João Gaspar Simões (1966, p.18) reconhece a importância dessa comunicabilidade quando, comentando sobre a linguagem experimental de Almeida Faria, nota nela a ausência de uma dimensão significativa mais ampla, para além do "artifício verbal, da não-dimensão humana [porque], com ou sem justificação científica, a palavra é sempre palavra, desde que a não penetre o pensamento, um pensamento feito vida, como é da praxe do romance, pese a quem pesar".
} 
hermenêutica de Ricoeur, importante como referência teórica para a análise da motivação bíblica de A paixão, uma vez que tal hermenêutica interessa-se principalmente pela interpretação da Escritura. Segundo Ricoeur, a palavra ou motivo bíblico não é simplesmente auto-refencial ou referente ao simbolismo religioso metanóico (internalizado no leitor e crente), mas também de referencialidade externa, na medida em que advoga uma conexão com a realidade física e histórica (RICOEUR, 1974, p.384). Por outro lado, considerando-se, como o faz A. J. Greimas (1979), o caráter especifico das transformações diacrônicas, é de se constatar que a irreversibilidade das suas aplicações é de difícil sistematização em termos de análise crítica. É com atenção voltada para esse impasse teórico que o material simbólico de $A$ paixão deve ser considerado ao se propor a sua descodificação em termos de referencialidade histórica. E isto poderá ser feito se se reconhecer uma relativa autoridade que o próprio autornarrador, em perspectiva metadiegética, parece conseguir devido não só à sua estratégia de distanciamento didático e experimental mas ainda, e sobretudo, devido à sua artística e independente inventividade e criação poética, descomprometida com os recursos miméticos tradicionais em termos de forma e estrutura do discurso narrativo ${ }^{10}$.

O componente histórico, a realidade contextual de A paixão, instaura-se por meio de um processo desmitificador da ilusão ficcional, quando o autor-narrador declara, com característico didatismo desfamiliarizador, textualmente no seu discurso: "Talvez o homem ressuscite no sábado; porque não? só o homem ressuscita a cada ano e o crucificado não é mais do que um símbolo muito nítido para a morte e ressurreição do próprio homem (...)" (FARIA, 1982, p.147). Essa declarada metadiegese narrativa, se não compromete a construção simbólica da sua mitopoesia, por outro lado, justifica a ligação entre poesia e realidade histórica. $\mathrm{Na}$ verdade, são realmente várias as passagens em que, paradigmaticamente e em compasso com a construção metafórica, o contexto cultural se compõe ao nível temático. Assim, a metafórica imagem da necessidade da vida e evasão das estruturas mortas, a qual adquire substância universal através da realidade dos arquétipos míticos, define-se circunstancialmente em relação a vários aspectos sociais colocados em amplas perspectivas histórico-culturais. Por exemplo, através da constatação da falência moral

\footnotetext{
${ }^{10}$ Nesse aspecto, a capacidade de recriação poética em Almeida Faria qualifica-se em consonância com o que Philip Rahv (1969, p.112-113) comenta sobre o poder de liberação que a simbolização mitopoética adquire na literatura: "this liberation is achieved not because the mind throws aside the sensuous forms of word and image, but because it uses them both as organs of its own, and thereby recognizes them for what they really are: form of its own self-revelations". Por outro lado, a crítica tem imediatamente reconhecido, na linguagem de Almeida Faria, uma expressão de densas interioridades, semelhante ao que Taborda de Vasconcelos (1968, p.117) chama de presença de uma espécie de "confissão psicanalítica".
} 
da classe patriarcal aburguesada, o autor-narrador, ao comentar sobre o trabalho serviçal de Piedade, analisa, em perspectiva histórica, certas condições políticas do operariado,

tendo nas mãos os elementos [isto é, a interação com os bens de produção essenciais à vida material], o mundo inteiro que ela merece, ela e a sua classe, passo primeiro e necessário para a vida dos outros, vida não alienada, não nos limites do estômago, nos quais afinal de contas acabou por cair, depois dessa viagem sabotada que se chamou revolução francesa e que os burgueses se encarregaram de estragar, sendo hoje necessária revolução mais radical, capaz de acabar com esta exploração desembestada que a besta burguesia burocrática inventa sempre com as mais sutis máscaras (... ).

FARIA (1982, p.124-125)

Apesar de todas as personagens, em maior ou menor grau, estarem sujeitas a essa referência estrutural, João Carlos, devido à sua condição de estudante de direito e de livre pensador, é quem mais sintoniza, com estratégias epistemológicas, essa problemática, analisando-a criticamente sob o prisma da sua formação humanística. A personagem não só se inquieta com a prevalência social do status quo da sua classe abastada, moral e culturalmente desfuncionalizada, mas também situa ideologicamente a possibilidade de sua superação em termos políticos e revolucionários, sentindo-se numa "solidão excessiva e estéril de ver que o mundo se renova e eu sou sempre o mesmo, novo velho, idoso jovem, filho duma classe morta, como Cristo morta, sem esperança de salvação ou redenção senão em outra classe, a classe nova, o proletariado?" (FARIA, 1982, p.116). Embora João Carlos não indique claramente uma afiliação em termos de credo político-reformista ${ }^{11}$, seu neo-humanismo ativista - que também é o de todo o discurso de Almeida Faria - define o que Oliveira (1980, p.53) chama de "temática social (...) concretizada, no seu termo, pela necessidade de pegar em armas e pela imagem da revolução (...).

A mudança social proposta revolucionariamente constitui a emancipação semânticoideológica da arquetipia simbólica figurada no discurso polissêmico de A paixão. Apesar de sua tonalidade trágica, o encaminhamento final desse discurso é cômico, no sentido de que o apocalíptico mitopoético transforma-se numa esperança de nova harmonização histórica através da luta dialética sócio-moral e material. Sobre isso João Carlos, epitomizando a disposição desejosa das personagens em geral, diz que

o nosso tempo não chegou ainda, há uma voz distante, uma reminiscência, eco sem fim, que devorou o velho esquecimento, mas quando vier a hora, havemos de estar preparados, acordados (...).

FARIA (1982, p.49)

\footnotetext{
11 Sobre a presença da política na ficção, Almeida Faria, numa entrevista concedida a Fernando Dacosta, comenta que o escritor deve tratar dos temas mais urgentes do seu tempo, mas que "isto não quer dizer que o escritor seja deliberadamente político ou faça romances de propaganda, que são sempre maus. Mas se o escritor fala das coisas que acontecem no seu país, tem de ser por força social e político" (DACOSTA, 1966, p.10).
} 
é preciso, porém estar preparado antes de vir o dia, e ouvir os mais pequenos movimentos da noite pesada de seus velhos monstros paquidérmicos; é necessário que durmas vigilante, descanses desperto; saibas o sabor negro do tempo; e que sejas por fim o próprio tempo (...) (ibidem, p.140-141).

Entretanto, como no seu substrato mitopoético e arquetípico, tal apocalipse histórico tem que se escarmentar com o sentido expiatório do pharmakos, agora em referência sócioeconômica à política do governo português totalitário das décadas 50-60 e de seus mecanismos como, por exemplo, a PIDE persecutória e torturante, o verdadeiro demonismo histórico de A paixão (FARIA, 1982, p.109-110, 140-141). O tradicional conceito do arquétipo apocalíptico místico-cristão, pseudamente histórico, torna-se, entretanto, insuficiente para a promessa dessa libertação assim condicionada. Isto porque tal conceito de regeneração paliativa-espiritual, conforme a define Eliade (1959, p.129-130) através da noção de metanoia, ainda representa intrinsicamente a ideologia de um redentor socialismo arcaico na linha das reformas do século XIX, as quais propunham uma contemporizadora e demorada reforma baseada em mudanças sociais apenas ao nível do individual. Esse tipo de libertação encontra o seu corolário num misticismo-crístico, o illud tempore apocalíptico, explicado por Eliade na seguinte passagem:

For him who shares in this eterna1 nunc of the reign of God, history ceases as totally as it does for the man of the archaic cultures, who abolishes it periodically. Consequently, for the Christian too, history can be regenerated, by and through each individual believer, even before the Savior's second coming, when it will utterly cease for a11 Creation (ELIADE, 1959, p.129130).

Opostamente a esse "eternal nunc", o conceito de apocalíptico histórico de A paixão parece afinar-se com a pragmática política na linha de Tony Stoneburner (1972, p.247-248) que, criticando o universalismo das categorias arquetípicas de Frye, conclui que elas não representam histórica e concretamente as necessidades verdadeiras do homem, porque "in the self understanding of persons who belong to an apocalyptic community, what oppresses is not epistemological or psycological but institutional and what threatens is not chaos of sensation or imagery but arrest, imprisonment, death externally and apostasy internally”.

Finalmente, assim considera Stoneburner essa problemática relacionada à apocalíptica literatura reformista e, ao que tudo indica, revolucionária: "If the apocalyptic promise of the end foreshortens the future it does so to sponsor and support faithfulness in the present. The irnportance of the work for the member of its original community was NOW" (STONEBURNER, 1972, p.247-248). É de se crer que A paixão, de Almeida Faria, deva ser considerada em relação a esse sentido imediatista ao tratar da reforma social proposta revolucionariamente em perspectivas políticas e históricas. E isso parece ser o caso, se for 
considerada a consciência do autor no tratamento do seu discurso literário, o seu cuidado em atualizar o seu texto (a revisão que faz para terceira edição do livro), agora muito mais comprometido com a atualidade histórica ${ }^{12}$. Entretanto, Almeida Faria, até chegar a essa versão final de A paixão, deixa cuidadosamente construída uma funcional combinação entre arte e realidade, justificando a sua artisticidade figurativa que, em termos de composição estrutural dos seus motivos ${ }^{13}$, não deixa de justificar o seu papel de renovador nos quadros da literatura portuguesa contemporânea.

\section{Referências}

ANGENOT, Marc. Glossário da crítica contemporânea. Trad. Miguel Tamen. Lisboa: Editorial Comunicação, 1984.

CAMPBELL, Joseph. Bios and Mythos: Prologomena to a Science of Mythology. In: VICKERY, John B. (Ed.) Myth and Literature: Contemporary Theory and Practice. Lincoln: University of Nebrasca Press, 1969, p. 7-23.

CAMPOS, Haroldo de. Serafim Ponte Grande: um grande não-livro. In: ANDRADE, Oswald de. Serafim Ponte Grande, Obras Completas, vol. 11. Rio de Janeiro: Civilização Brasileira, 1971, p. 2-9.

O seqüestro do barroco na Formação da literatura brasileira: o caso Gregório de Matos. Salvador: Fundação Casa Jorge Amado, 1989.

CASSIRER, Ernst. The Philosophy of Symbolic Forms. New Haven: Yale University Press, 1957.

CHIAMPI, Irlemar. O realismo maravilhoso. São Paulo: Editora Perspectiva, 1980.

CRUZ, Liberto. Um novo romancista, Diário de Lisboa, p. 11-12, 18 mai. 1966.

CIRLOT, J. E., A Dictionary of Symbols. Trad. Jack Sege. New York: Philosophical Library, 1962.

\footnotetext{
12 Jack E. Tomlins (1981, p.341, n. 13), comparando as primeiras edições de A paixão, aponta para essa consciência histórica do seu autor. Nesse sentido, comenta que a revisão do texto da terceira edição "is considerably more dramatic in its post-revolution version", referindo-se aqui, evidentemente, à revolução do regime político português acontecida em Abril de 1974.

${ }^{13}$ Recorda-se aqui o comentário de Benedito Nunes $(1966$, p.9) sobre a solução para o encerramento do livro, cuja "síntese pouco significativa e muito retórica dos símbolos anteriores", motivada pela "ênfase de associações intencionalmente dirigidas, óbvias e até certo ponto ingênuas", coloca o autor-narrador num verdadeiro impasse em como concluir a sua narrativa: "Como concluí-la, se os acontecimentos decisivos, transferidos para um futuro utópico, permanecem em suspenso, simbolicamente sugeridos?".
} 
DACOSTA Femando. Diálogo com Almeida Faria, Comércio do Funchal, p. 9-11, 15 abr. 1966.

ELIADE, Mircea. Cosmos and History: The Myth of the Eternal Return. Trad. Willard R. Trask. New York: Harper, 1959.

FARIA, Almeida. Entrevista, Artes e Letras, Lisboa, p. 18-19, mar. 1966.

. Criador é quem tira da realidade (...) O Século, Lisboa, p. 5-6, 17 jun. 1967.

. A paixão. In: FARIA, Almeida.Trilogia lusitana. Lisboa: Imprensa Nacional-Casa da Moeda, 1982.

FONTEROSE, Joseph. The Ritual Theory of Myth. Berkeley: University of California Press, 1966.

FRANK, Manfred. Die Dichtung als 'Neue Mythologie'. In: Mythos und Moderne. Frankfurt am Maim: Suhrkamp, 1983, p. 1-37.

FRYE, Northrop. Fables of Identity. New York: Harcourt, Brace and World, 1963.

. Anatomv of Criticism: Four Essays. New York: Atheneum, 1966.

.The Archetypes of Literature. In: VICKERY, John B. (Ed.) Myth and Literature: Contemporary Theory and Practice. Lincoln: University of Nebraska Press, 1969, p. 72115 .

GREIMAS, Algirdas Julien. Structure et Histoire. In: JOHNSON, A. M. Jr. (Ed.) Structuralism and Biblical Hermeneutics. Pittsburgh: Pickwick Press, 1979.

HARTMAN, Geoffrey H. Beyond Formalism. New Haven: Yale University Press, 1970.

HOLANDA, Sérgio Buarque de. Visão do paraíso: os motivos edênicos no descobrimento e colonização do Brasil. São Paulo: Companhia Editora Nacional, 1969.

KERMODE, Frank. The Sense of an Ending: Studies in the Theory of Fiction. New York: Oxford University Press, 1967.

KNUTSON, Harold C. Molière: An Archetypal Approach. Toronto: University of Toronto Press, 1976.

MACHADO Álvaro Manuel. A novelística portuguesa contemporânea. Lisboa: Instituto de Cultura e Língua Portuguesa, 1984.

MELO E CASTRO, Ernesto Manuel de. Literatura portuguesa de invenção. São Paulo: Difel, 1984.

MENDONÇA, Fernando. A literatura portuguesa no século XX. Assis: HUCITEC, 1973

OLIVEIRA, Cristina Robalo Cordeiro. A paixão de Almeida Faria. Coimbra: Instituto Nacional de Investigação Científica, 1980. 
NUNES, Benedito. Paixão de um romancista, Suplemento Literário do Estado de São Paulo, São Paulo, p. 9-10, 24 out. 1966.

PANIKKAR, Raimon. Myth, Faith and Hermeneutics: Cross Cultural Studies. New York: Paulist Press, 1979.

RICOEUR, Paul. The Conflict of Interpretations: Essays in Hermeneutics. Evanston: Northwestern University Press, 1974

RAHV, Philip.The Myth and the Powerhouse. In: VICKERY John B. (Ed.) Myth and Literature: Contemporary Theory and Practice. Lincoln: University of Nebraska Press, 1969, p. 96-120.

SIMÕES, João Gaspar. 'A Paixão', romance por Almeida Faria. Crítica Literária, Lisboa, p. 17-18, jul. 1966.

STONEBURNER, Tony. Notes on Prophecy and Apocalypse in a Time of Anarchy and Revolution: A Trying Out. In: WHITE, George A. e NEWMAN, Charles (Eds.) Literature and Revolution. New York: Holt, 1972.

TOMLINS Jack E. Character and Structure in Almeida Faria's A Paixão. La Chispa (Proceedings / The $2^{\text {nd. }}$ Louisiana Conference on Hispanic Languages and Literatures), Louisiana, vol. 1, p. 333-342, 1981.

TORRES, Alexandre Pinheiro. O neo-realismo português. Lisboa: Moraes Editores, 1976.

WHITE, Hayden. The Content of the Form: Discourse and Historical Representation. Baltimore and London: Johns Hopkins University Press, 1989.

WHITE, John J. Mythology in the Modern Novel: A Study of Prefigurative Techniques. New Jersey: Princeton University Press, 1971.

VASCONCELOS, Taborda. Almeida Faria: A Paixão, O Médico, n. 880, Lisboa, p. 116-118, 1980. 